\title{
Short residence time and fast transport of fine detritus in the Judean Desert: Clues from ${ }^{7} \mathrm{Be}$ in settled dust
}

\author{
Reuven Belmaker, ${ }^{1,2}$ Boaz Lazar, ${ }^{1}$ Mordechai Stein, ${ }^{1,2}$ and Jürg Beer ${ }^{3}$ \\ Received 27 June 2011; revised 17 July 2011; accepted 24 July 2011; published 31 August 2011.
}

[1] The cosmogenic isotope ${ }^{7} \mathrm{Be}\left(\mathrm{t}_{1 / 2}=53.3 \mathrm{~d}\right)$ was measured in sediments collected from dust traps deployed in the Judean Desert which is part of the Dead Sea drainage basin. The results show that (a) the ${ }^{7} \mathrm{Be}$ dry deposition flux in the Dead Sea region is $2.0 \pm 0.6 \times 10^{4}$ atoms $\mathrm{cm}^{-2} \mathrm{y}^{-1}$ during summer and winter and $5.3 \pm 0.7 \times 10^{4}$ atoms cm $^{-2} \mathrm{y}^{-1}$ during fall; (b) the residence time of dust in the Dead Sea drainage basin is less than one year; (c) the recycled component of the cosmogenic isotope ${ }^{10} \mathrm{Be}\left(\mathrm{t}_{1 / 2}=1.3910^{6} \mathrm{y}\right)$ in Judean desert dust is potentially small; and (d) the ${ }^{7}$ Be inventory (atoms $\mathrm{cm}^{-2}$ ) in dust settled in the drainage basin did not reach steady state between consecutive rare events of desert winter floods suggesting a short transport rate of fine detritus material from the marginal terraces into the Dead Sea. Provided ${ }^{10} \mathrm{Be}$ behaves similarly (as implied by the common geochemistry and cosmogenic origin of ${ }^{7} \mathrm{Be}$ and ${ }^{10} \mathrm{Be}$ ), we suggest ${ }^{10} \mathrm{Be}$ in Lake Lisan (Pleistocene Dead Sea) detrital sediments as a potential proxy for paleo-flood frequency and dust transport. Citation: Belmaker, R., B. Lazar, M. Stein, and J. Beer (2011), Short residence time and fast transport of fine detritus in the Judean Desert: Clues from ${ }^{7} \mathrm{Be}$ in settled dust, Geophys. Res. Lett., 38, L16714, doi:10.1029/2011GL048672.

\section{Introduction}

[2] The cosmogenic isotopes ${ }^{10} \mathrm{Be}\left(\mathrm{t}_{1 / 2}=1.39 \mathrm{Ma}\right)$ and ${ }^{7} \mathrm{Be}\left(\mathrm{t}_{1 / 2}=53.3\right.$ days $)$ are produced mainly in the upper atmosphere by spallation of oxygen and nitrogen due to their interaction with cosmic ray particles. The production rate of these isotopes is dependent on the cosmic ray flux penetrating into the atmosphere, which in turn is modulated by the heliomagnetic and the geomagnetic field. After production, these beryllium nuclides attach to aerosols and are quickly removed from the atmosphere mainly via wet and dry (dust) precipitation. If ${ }^{10} \mathrm{Be}$ is not recycled, then its inventories in annual lacustrine laminae (varves) are potential high-resolution archives of the ${ }^{10} \mathrm{Be}$ production rate [Belmaker et al., 2008]. However, the ${ }^{10} \mathrm{Be}$ recycled component which is a consequence of the long half-life of ${ }^{10} \mathrm{Be}$, can not be determined just by comparing between the ${ }^{10} \mathrm{Be}$ production rate and its distribution in terrestrial reservoirs. Nevertheless under certain assumptions it is possible to evaluate the recycled ${ }^{10} \mathrm{Be}$ component by

\footnotetext{
${ }^{1}$ Institute of Earth Sciences, Hebrew University of Jerusalem, Jerusalem, Israel.

${ }^{2}$ Geological Survey of Israel, Jerusalem, Israel.

${ }^{3}$ EAWAG, Duebendorf, Switzerland.
}

Copyright 2011 by the American Geophysical Union. 0094-8276/11/2011GL048672 measuring the much shorter living nuclide, ${ }^{7} \mathrm{Be}$, which has similar geochemistry but its dry deposition under hyper arid conditions can be considered to have virtually no recycled component.

[3] Globally, dry deposition of cosmogenic beryllium is much smaller than its wet deposition [Field et al., 2006; Heikkila et al., 2009], hence, it is generally neglected [Olsen et al., 1985; Todd et al., 1989; Turekian et al., 1983]. In desert areas however dry deposition is the major supply of "newly" produced cosmogenic beryllium.

[4] Here we describe an attempt to estimate the ${ }^{7} \mathrm{Be}$ dry deposition flux and use it as a proxy to evaluate the recycled ${ }^{10} \mathrm{Be}$ component. The study was conducted in Darga Wadi, a dry river in the Judean Desert, Israel, part of the drainage area of the Dead Sea and its late Pleistocene precursor, Lake Lisan (Figure 1). Darga Wadi is located in an arid region in which long drought periods separate rare and short lasting (a few hours) winter flood events. Hence, it is potentially an ideal site for measuring the dry deposition of cosmogenic beryllium and evaluating the importance of recycling in the accumulation of ${ }^{10} \mathrm{Be}$.

[5] The data collected in the study enabled us to estimate simultaneously the dry deposition flux of ${ }^{7} \mathrm{Be}$ and the recycled component of ${ }^{10} \mathrm{Be}$ in the Dead Sea region. These estimations are necessary for assessing the potential of using the ${ }^{10} \mathrm{Be}$ in the detrital lacustrine sediments (washed into the lake by rare winter flood events) of Lake Lisan (Late Pleistocene precursor of the Dead Sea) as a paleo-production archive and/or monitor of paleo-flood frequency.

[6] Lake Lisan and the Dead Sea occupied the tectonic depressions along the Dead-Sea-Transform during the last glacial and the Holocene periods, respectively [Begin et al., 1974; Neev and Emery, 1967; Stein, 2001]. The lakes are located to the east of the Judean Mountains whose eastern side comprises the rain shadow Judean Desert. Rains that precipitate on the Judean Mountains generate winter floods that run down to the lakes through the Judean Desert. The floods and the Jordan River that enters the lake at its northern tip supply to the lakes dissolved and particulate matter. The freshwater supplies bicarbonate and sulfate to the $\mathrm{Ca}$-chloride brine that fills the lake causing the deposition of primary aragonite and gypsum [Katz et al., 1977; Stein et al., 1997]. Flood waters bring also silty-detritus material composed mainly of quartz and calcite particles that are considered as desert dust that was (and is) derived and transported to the watershed mainly from the Sahara and Negev deserts [HalivaCohen, 2004; Singer et al., 2003; Yaalon and Ganor, 1975]. After settling on the surface of the watershed the dust is washed by the irregular winter floods into the lake. The winter floods are short and continue for only a few hours 


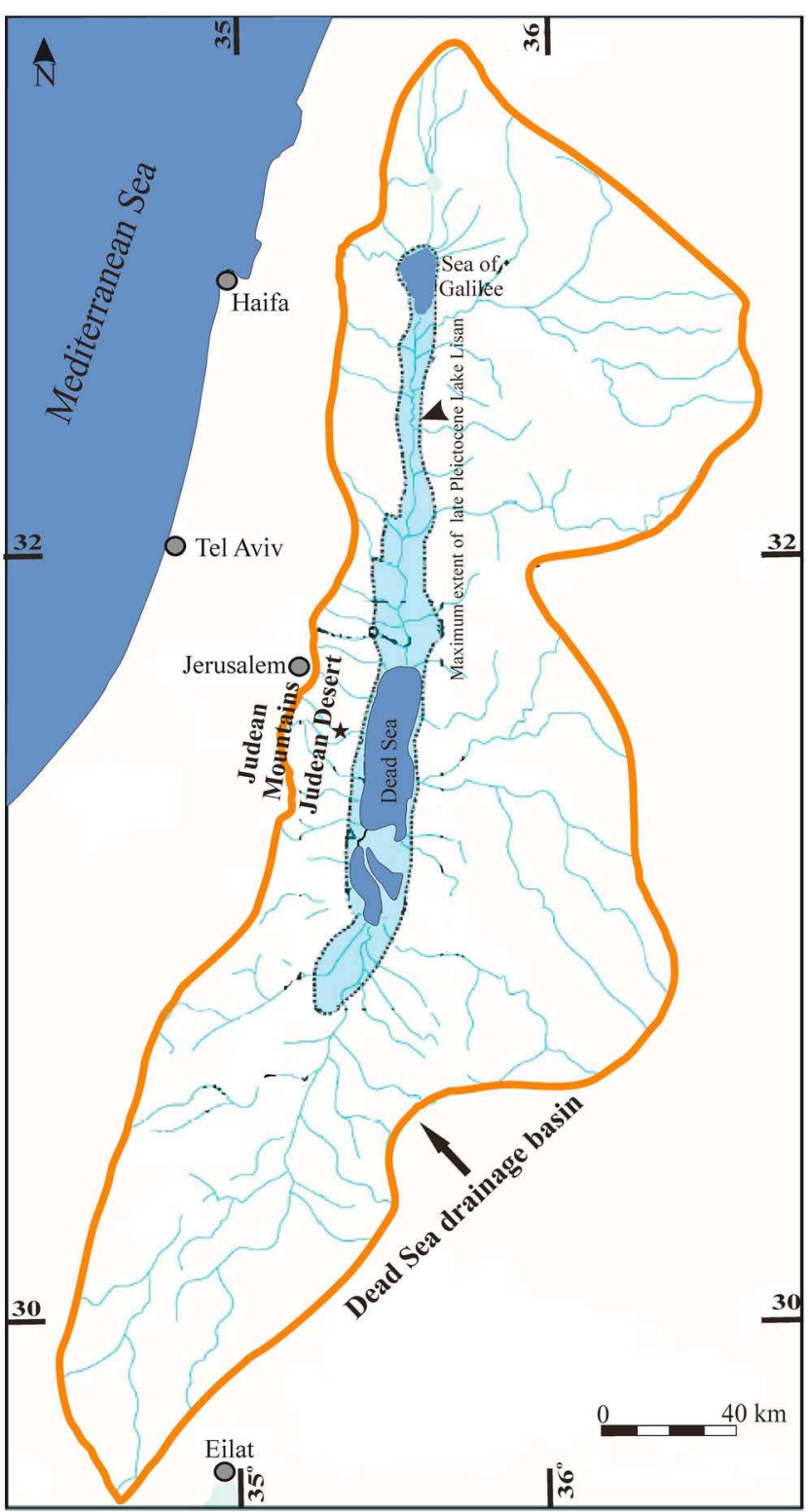

Figure 1. Location map showing the Dead Sea, its drainage basin, the maximum extent of the Pleistocene Lake Lisan and the sampling site in the Darga Wadi (marked by the black star).

[Greenbaum et al., 2006]. Most of the year the area is precipitation free.

\section{Sampling and Analytical Methods}

[7] The dust settled in the drainage basin was collected by rinsing with distilled water pebbles along the Darga Wadi in the Judean Desert (Figure 1). The pebbles were washed in a box equipped with a water collection funnel and the rinse water was collected together with the dust (Figure 2a). The washed dust-free pebbles were placed back on a nylon sheet and left in the field to collect solids for a pre-determined period (Figure $2 b$ ). Four nylon sheets covered with pebbles (dust-traps) were left in the field to be recovered after different time intervals of up to $78 \mathrm{~d}$ (Table 1). As mentioned the sampling site is located in a desert with long drought periods and no unpredicted rain. This enabled us to be sure that during sampling intervals no rain precipitated in the sampling site. In the case of a rain forecast, samplers were collected thus terminating the sampling interval.

[8] At the end of each dust collection period, the nylon sheet with the pebbles was carefully removed, inserted into the wash-box, washed with deionized water and the solids and water were collected for ${ }^{7} \mathrm{Be}$ analyses. This sampling procedure simulates natural settling conditions of airborne particles in the Dead Sea drainage area and was designed to avoid problems stemming from sampler bias [Duenas et al., 2009].

[9] The dust washed from the pebbles was dried in an oven at $105{ }^{\circ} \mathrm{C}$ and the ${ }^{7} \mathrm{Be}$ was analyzed by $\mathrm{Ge}-\gamma$ spectrometer in the laboratories of the Swiss Federal Institute of Environmental Science and Technology (EAWAG).

\section{Results and Discussion}

\subsection{The ${ }^{7} \mathrm{Be}$ in Dust Traps}

[10] The ${ }^{7} \mathrm{Be}$ inventory (atoms $\mathrm{cm}^{-2}$ ) in the dust traps (Figure 2) increased steadily with time since their deployment, showing a clear level off towards a steady state (Table 1 and Figure 3). The ${ }^{7} \mathrm{Be}$ increase was higher during the fall (traps deployed during November and December) than during summer-winter (traps deployed during July-October and January). The data shows that the concentration of ${ }^{7} \mathrm{Be}$ in the dust collected during a major dust storm was more than an order of magnitude higher than the regular average (last row in Table 1). It appears therefore that the higher the amount of dust transported, the higher the concentration of ${ }^{7} \mathrm{Be}$ in the dust. Because a dilution effect is expected this observation is surprising. A possible explanation for this observation is that large dust storms erode more topsoil that is rich in ${ }^{7} \mathrm{Be}$. However, previous studies [Haliva-Cohen, 2004] have shown that the source of Judean Desert dust is the Saharan and Negev deserts. Since these are arid regions with virtually no rain that can contribute to the ${ }^{7} \mathrm{Be}$ concentration in the eroding soil we assume that prior to its transport in the atmosphere the ${ }^{7} \mathrm{Be}$ concentration was very low. This assumption is in accordance with Kaste et al. [2011] who showed that the ${ }^{7} \mathrm{Be}$ concentration in eroding arid regions is low. Thus, we suggest the higher the overall dust transport the higher the cosmogenic beryllium it scavenges. A similar correlation between ${ }^{7} \mathrm{Be}$ and dust load was observed for the transport of Saharan dust to the island of Tenerife [Hernandez et al., 2008].

[11] Observations on the dust flux in the region showed a clear seasonality [Singer et al., 2003]: high dust flux during falls and springs and low during winters and summers. The similarity between the seasonal patterns of the ${ }^{7} \mathrm{Be}$ inventory in the traps and the measured dust flux indicates that the higher the flux of airborne material, the higher the ${ }^{7} \mathrm{Be}$ concentration (atoms $\cdot \mathrm{g}^{-1}$ ) in the dust. This phenomenon strongly suggests that the higher the amount of dust suspended in the atmosphere the higher its ${ }^{7} \mathrm{Be}$ (and ${ }^{10} \mathrm{Be}$ ) "scavenging efficiency" and that the drainage basin (represented by the dust traps) is continuously replenished with "fresh" atmospheric ${ }^{7} \mathrm{Be}$. The dependence of "scavenging efficiency" on the amount of suspended dust is corroborated by the high ${ }^{7} \mathrm{Be}$ in the trap material collected after a major dust storm (Table 1 and section 3.2 below). 


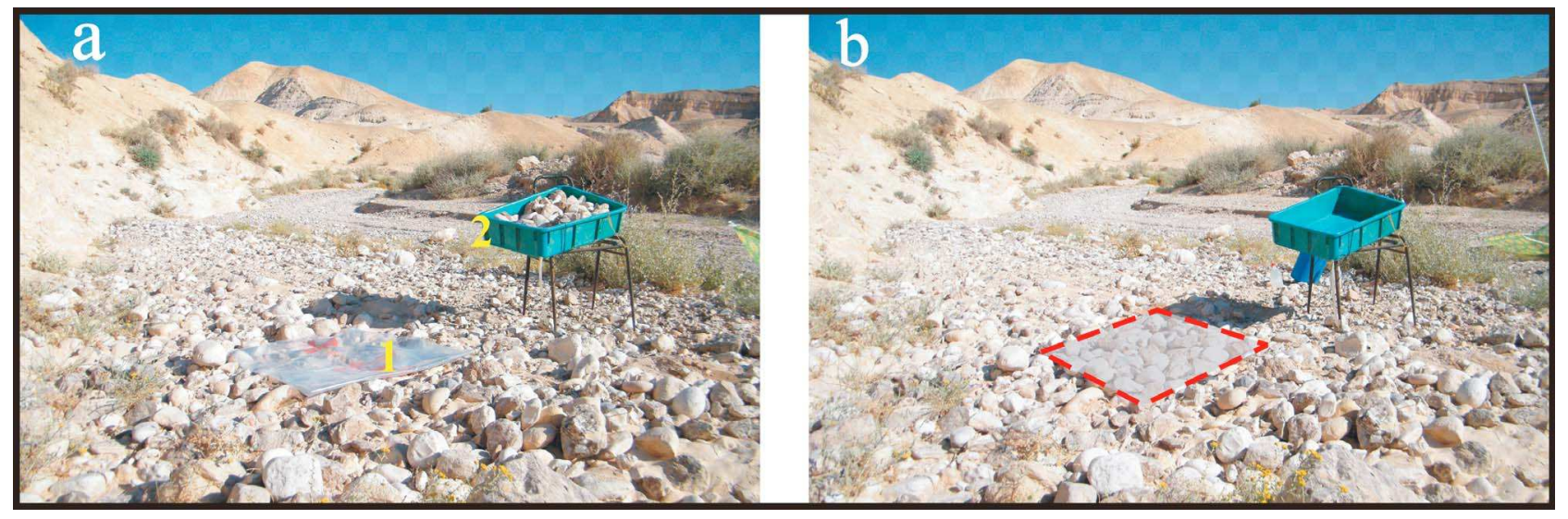

Figure 2. The dust sampling setup in Darga Wadi. (a) The site showing the dust trap (the semi-transparent nylon sheet marked by \#1) and the pebbles washing box (\#2) full with washed pebbles. (b) The site after trap deployment for collecting dust; the washed pebbles were placed over the nylon sheet (shaded area surrounded by dashed line) until next dust sampling. The four dust traps were deployed in the area at a distance of $\sim 2 \mathrm{~m}$ from each other.

\subsection{Mass-Balance Model of ${ }^{7}$ Be Dry Deposition in the} Dead Sea Drainage Basin

[12] Considering the conclusion above (section 3.1), we constructed a first order rate law model describing the massbalance of the ${ }^{7} \mathrm{Be}$ inventory in the Dead Sea drainage basin.
The model is relevant for dry periods during which the ${ }^{7} \mathrm{Be}$ accumulates in the drainage basin before its transport by winter floods into the Dead Sea. The model is comprised of just two terms: ${ }^{7} \mathrm{Be}$ input by direct atmospheric dry deposition and output by radioactive decay. The mass-balance of the

Table 1. Summary of ${ }^{7}$ Be Data for the Dust Trap Deployments

\begin{tabular}{|c|c|c|c|c|c|c|c|c|}
\hline Name & $\begin{array}{c}\text { Dust Trap } \\
\text { Placement } \\
\text { Date }\end{array}$ & $\begin{array}{c}\text { Dust Trap } \\
\text { Recovery } \\
\text { Date }\end{array}$ & $\begin{array}{l}\text { Dust Trap } \\
\text { Deployment } \\
\text { Period (d) }\end{array}$ & $\begin{array}{c}\text { Material } \\
\text { Recovered } \\
\text { (gr) }\end{array}$ & $\begin{array}{c}\text { Trap Area } \\
\left(\mathrm{cm}^{2}\right)\end{array}$ & $\begin{array}{c}{ }^{7} \mathrm{Be} \\
\left(\times 10^{6} \text { at } \mathrm{gr}^{-1}\right)\end{array}$ & $\begin{array}{l}\text { Counting } \\
\text { Error } \\
(\%)\end{array}$ & $\begin{array}{c}{ }^{7} \mathrm{Be} \\
\left(\times 10^{3} \text { at } \mathrm{cm}^{-2}\right)\end{array}$ \\
\hline \multicolumn{9}{|c|}{ Initial Pebbles } \\
\hline $\mathrm{DRD}^{\mathrm{a}}$ & 27.07 .08 & 27.07 .08 & - & 15.4 & - & 0.385 & 16 & - \\
\hline DRD $7^{\mathrm{b}}$ & 11.11 .08 & 11.11 .08 & 0 & 7.8 & 4900 & 1.05 & 18 & 1.67 \\
\hline DRD8 & 11.11 .08 & 11.11 .08 & 0 & 7.3 & 4900 & 0.625 & 20 & 0.927 \\
\hline \multicolumn{9}{|c|}{ Summer-Winter Samples } \\
\hline DRD3 & 27.07 .08 & 24.08 .08 & 28 & 6.5 & 4900 & 0.698 & 13 & 0.925 \\
\hline DRD1789_1499A & 17.08 .09 & 14.09 .09 & 29 & 8.7 & 5625 & 0.319 & 38 & 0.492 \\
\hline DRD1789_1599B & 17.08 .09 & 15.09 .09 & 30 & 9.6 & 5625 & 0.213 & 47 & 0.361 \\
\hline DRD1599_2099 & 15.09 .09 & 20.09 .09 & 5 & 6.3 & 5625 & 0.352 & 34 & 0.392 \\
\hline DRD 4 & 24.08 .08 & 28.09 .08 & 35 & 6.0 & 4900 & 1.02 & 12 & 1.25 \\
\hline DRD2 & 25.09 .08 & 08.10 .08 & 14 & 6.1 & 4900 & 0.312 & 17 & 0.389 \\
\hline DRD17129/1719 & 17.12 .09 & 17.01.10 & 31 & 4.6 & 5625 & 2.02 & 9 & 1.66 \\
\hline DRD25119/17110A & 25.11 .09 & 17.01.10 & 53 & 7.7 & 5625 & 2.21 & 9 & 3.04 \\
\hline DRD17129/17110 & 17.12 .09 & 17.01 .10 & 31 & 4.2 & 5625 & 2.01 & 18 & 1.51 \\
\hline DRD25119/17110-B & 25.11 .09 & 17.01.10 & 53 & 5.6 & 5625 & 2.41 & 6 & 2.50 \\
\hline \multicolumn{9}{|c|}{ Fall Samples } \\
\hline DRD2099/1119 & 20.09 .09 & 01.11 .09 & 42 & 8.5 & 5625 & 3.61 & 18 & 5.43 \\
\hline DRD1499/1119 & 14.09 .09 & 01.11 .09 & 48 & 11.8 & 5625 & 2.63 & 13 & 5.53 \\
\hline DRD1499/2199 & 14.09 .09 & 02.11 .09 & 49 & 11.3 & 5625 & 2.25 & 17 & 4.50 \\
\hline DRD14 & 29.10 .08 & 11.11 .08 & 14 & 7.1 & 5625 & 1.29 & 18 & 1.62 \\
\hline DRD1199/17119 & 11.09 .09 & 17.11 .09 & 67 & 16.3 & 5625 & 2.22 & 15 & 6.43 \\
\hline DRD1119/17119 & 1.11 .09 & 17.11 .09 & 17 & 10.8 & 5625 & 1.38 & 20 & 2.66 \\
\hline DRD17119/25119-C & 17.11 .09 & 25.11 .09 & 8 & 5.5 & 5625 & 2.44 & 12 & 2.39 \\
\hline DRD1119/25119 & 1.11 .09 & 25.11 .09 & 25 & 13.8 & 5625 & 1.96 & 9 & 4.82 \\
\hline DRD17119/25119-B & 17.11 .09 & 25.11 .09 & 8 & 3.9 & 5625 & 3.40 & 12 & 2.38 \\
\hline DRD2119/25119 & 2.11 .09 & 25.11 .09 & 23 & 6.8 & 5625 & 2.98 & 7 & 3.58 \\
\hline DRD2099/7129 & 20.09 .09 & 07.12 .09 & 78 & 12.3 & 5625 & 2.78 & 10 & 6.08 \\
\hline DRD25119/7129-C & 25.11 .09 & 07.12 .09 & 12 & 2.7 & 5625 & 2.02 & 27 & 0.971 \\
\hline DRD7129/17129 & 7.12 .09 & 17.12 .09 & 10 & 4.8 & 5625 & 1.62 & 26 & 1.39 \\
\hline DRD25119/17129 & 25.11 .09 & 17.12 .09 & 22 & 6.6 & 5625 & 1.48 & 21 & 1.74 \\
\hline \multicolumn{9}{|c|}{ Dust Storm } \\
\hline GMD-131210 & & 13.12 .10 & - & - & - & 45 & 7 & - \\
\hline
\end{tabular}

${ }^{\mathrm{a}}$ Initial dust (see Figure 3).

${ }^{\mathrm{b}}$ Relatively small pebbles.

${ }^{\mathrm{c}}$ Small dust storm before sampling. 


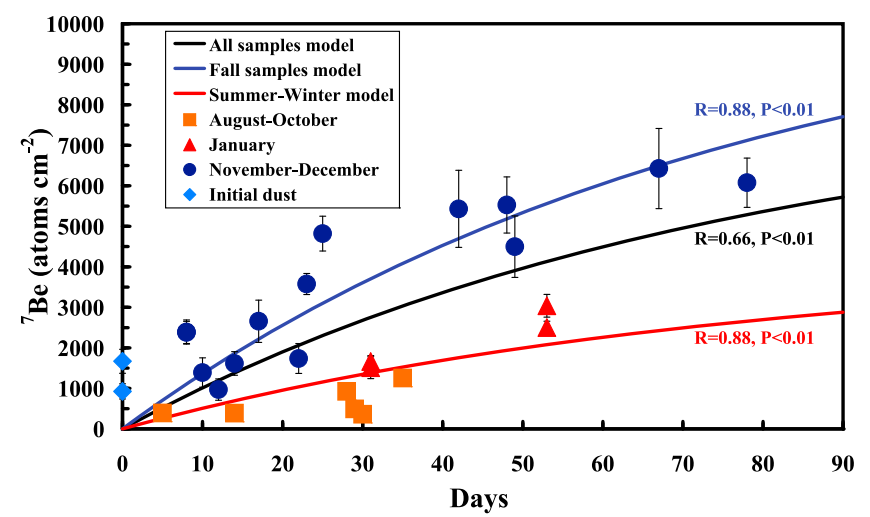

Figure 3. The ${ }^{7} \mathrm{Be}$ inventory versus sampling time in the dust traps for the two deployment seasons. Solid curves represent the best fit for the mass-balance model (equation (2)). Correlation coefficients (R) and $\mathrm{P}$ values for the two seasons and for the curve representing all data average are indicated on the curves. The diamond markers (Initial dust in the legend) are the ${ }^{7} \mathrm{Be}$ values of the dust washed from the pebbles immediately after their collection in the field before their deployment in the dust traps (see section 3 and Figure 2).

${ }^{7} \mathrm{Be}$ inventory (atoms $\cdot \mathrm{cm}^{-2}$ ) in the drainage basin (e.g., dust traps) is described by the equation:

$$
\frac{\mathrm{d}^{7} \mathrm{Be}(\mathrm{t})}{\mathrm{dt}}=\mathrm{F}_{7_{\mathrm{Be}}}(\mathrm{t})-\lambda_{7} \cdot{ }^{7} \mathrm{Be}
$$

where $\mathrm{F}_{7_{\mathrm{Be}}}(\mathrm{t})$ is the atmospheric ${ }^{7} \mathrm{Be}$ flux into the drainage basin (atoms $\cdot \mathrm{cm}^{-2} \cdot \mathrm{d}^{-1}$ ) and $\lambda_{7}$ is the decay constant of ${ }^{7} \mathrm{Be}$ $\left(\mathrm{d}^{-1}\right)$. If ${ }^{7} \mathrm{Be}(0)=0$ and the ${ }^{7} \mathrm{Be}$ input flux is constant over a time interval of about $1 / \lambda_{7}(\mathrm{~F}(\mathrm{t})=\mathrm{F})$ than the solution of equation (1) is:

$$
{ }^{7} \operatorname{Be}(\mathrm{t})=\frac{\mathrm{F}_{7_{\mathrm{Be}}}}{\lambda_{7}}\left(1-\mathrm{e}^{-\lambda_{7} \mathrm{t}}\right)
$$

Where $\mathrm{F}_{7_{\mathrm{Be}}} / \lambda_{7}$ is the ${ }^{7} \mathrm{Be}$ inventory at steady state $\left({ }^{7} \mathrm{Be}_{(\infty)}\right)$.

[13] Equation (2) describes the time necessary to reach steady state for ${ }^{7} \mathrm{Be}$. Because of its half life $(53.3 \mathrm{~d})$ after $\sim 6$ months $\left(\sim 2.33 / \lambda_{7}\right)$ the ${ }^{7} \mathrm{Be}$ inventory reaches a practical steady state $(90 \%$ of the steady state value). Fitting equation (2) to the dust trap data for the two different sampling seasons (Figure 3 ) yields the fluxes of airborne ${ }^{7} \mathrm{Be}$ in the Dead Sea drainage area. The ${ }^{7} \mathrm{Be}$ fluxes for the Judean Desert calculated by the model are $2.0 \pm 0.6 \times 10^{4}$ atoms $\mathrm{cm}^{-2} \cdot \mathrm{y}^{-1}$ for the summer-winter sampling season and $5.3 \pm 0.7 \times 10^{4}$ atoms $\mathrm{cm}^{-2} \cdot \mathrm{y}^{-1}$ for the fall season. Fitting the model for all data collected yields an annual average flux of $3.9 \pm 0.8 \times 10^{4}$ atoms $\mathrm{cm}^{-2} \cdot \mathrm{y}^{-1}$. The calculated mean annual dry ${ }^{7} \mathrm{Be}$ flux in the Judean Desert is lower by factor of two than the dry ${ }^{7} \mathrm{Be}$ flux for Damascus, Syria estimated to be $7.8 \times 10^{4}$ atoms $\cdot \mathrm{cm}^{-2} \cdot \mathrm{y}^{-1}$ [Othman et al., 1998]. It should be noted however that for the prevailing summer-winter conditions the Judean Desert ${ }^{7} \mathrm{Be}$ flux estimated in this study is close to the flux estimated for Damascus. The variations between the sites may stem from storm variability that affect the atmospheric ${ }^{7} \mathrm{Be}$ flux [Hernandez et al., 2008].

[14] Steady state ${ }^{7} \mathrm{Be}$ inventories $\left({ }^{7} \mathrm{Be}_{(\infty)}=\mathrm{F}_{7_{\mathrm{Be}}} / \lambda_{7}\right)$ are estimated to be 4,200 atoms $\cdot \mathrm{cm}^{-2}$ for the summer-winter,
11,000 atoms $\cdot \mathrm{cm}^{-2}$ for the fall, and 8,200 atoms $\mathrm{cm}^{-2}$ for the annual average. Kaste et al. [2011] reported a much higher ${ }^{7} \mathrm{Be}$ inventory in the arid Owens valley, California $\left(\sim 1.25 \times 10^{5}\right.$ atoms $\left.\mathrm{cm}^{-2}\right)$. However, during his sampling period $\sim 15 \mathrm{~cm}$ of rain precipitated whereas during the sampling in this study no rain precipitated. Thus, a direct comparison is not possible.

[15] Steady state ${ }^{7} \mathrm{Be}$ inventories are considerably higher than the ${ }^{7} \mathrm{Be}$ inventory in dust samples obtained from the initially collected pebbles (prior to placing them in the traps; marked by the diamonds in Figure 3). Although this observation may result from incomplete collection of the initial ${ }^{7} \mathrm{Be}$ inventory, it suggests that ${ }^{7} \mathrm{Be}$ did not reach steady state during the dry season and the period between flood events. This implies that the residence time of Judean Desert dust in the Dead Sea drainage basin is less than one year. This is a rather short residence time for desert areas, indicating that rare flood events in the drainage basin wash very efficiently into the deposition basin the airborne particles that were deposited during the dry season. If this is true then the supply of ${ }^{7} \mathrm{Be}$ into the deposition basin (Dead Sea) depends on flood frequency. Short flood intervals (shorter than the residence time of ${ }^{7} \mathrm{Be}$ in the drainage basin) prevent the buildup of ${ }^{7} \mathrm{Be}$ in the drainage basin lowering its inventory in the deposition basin. If the input of ${ }^{10} \mathrm{Be}$ into the drainage basin is similar to that of ${ }^{7} \mathrm{Be}$ (see section 3.4. below) then the ${ }^{10} \mathrm{Be}$ stratigraphy in Lake Lisan sediments may provide a record of paleo-flood frequency. This hypothesis remains to be validated by simultaneous measurements of ${ }^{10} \mathrm{Be}$ and ${ }^{7} \mathrm{Be}$ on the dust trap samples.

\subsection{The Atmospheric Residence Time of ${ }^{7} \mathrm{Be}$}

[16] In order to calculate the atmospheric ${ }^{7} \mathrm{Be}$ residence time from the model presented above the recycled ${ }^{7} \mathrm{Be}$ in Judean desert dust was assumed to be negligible. This assumption was made on the basis that the source of the dust is in arid regions (see section 3.1 for detail) and on the basis of the good fit between the data and the model presented in section 3.2, i.e., a large ${ }^{7} \mathrm{Be}$ recycled component would lead to a large scattering of the data. Accordingly the atmospheric residence time of ${ }^{7} \mathrm{Be}, \tau$, is estimated by the following equation:

$$
\tau=\frac{1}{\lambda_{7}} \cdot \ln \left(\frac{\mathrm{P}_{7_{\mathrm{Be}}}}{\mathrm{F}_{7_{\mathrm{Be}}}}\right)
$$

Where $\mathrm{P}_{7_{\mathrm{Be}}}$ is the ${ }^{7} \mathrm{Be}$ production rate in the range of the Judean and Saharan deserts (latitude range of $\sim 30^{\circ}-40^{\circ} \mathrm{N}$ ), $2.4 \times 10^{3}$ atoms $\cdot \mathrm{cm}^{-2} \cdot \mathrm{d}^{-1}$ [Masarik and Beer, 1999]. The $\mathrm{P}_{7_{\mathrm{Be}}} / \mathrm{F}_{7_{\mathrm{Be}}}$ ratio in the Dead Sea drainage basin is $\sim 20\left(\mathrm{~F}_{7_{\mathrm{Be}}}\right.$ value taken from the calculation in section 3.2 above), meaning that $\sim 5 \%$ of the atmospherically produced ${ }^{7} \mathrm{Be}$ reaches the surface. Substituting the $\mathrm{P}_{7_{\mathrm{Be}}} / \mathrm{F}_{7_{\mathrm{Be}}}$ ratio into equation (3) yields a mean ${ }^{7} \mathrm{Be}$ atmospheric residence time in the Dead Sea region of $220 \pm 45 \mathrm{~d}$, and summer-winter and fall residence times of $290 \pm 60 \mathrm{~d}$ and $101 \pm 14 \mathrm{~d}$, respectively. It should be noted that the only ${ }^{7} \mathrm{Be}$ atmospheric loss term in equation (3) is radioactive decay $\left(\lambda_{7}\right)$. However, the atmospheric residence time of ${ }^{7} \mathrm{Be}$ depends also on its "scavenging" rate constant and the particles sinking rate. Therefore, the residence times estimated above are in fact the maximum residence times. Furthermore, due 
to the long stratospheric residence time of ${ }^{7} \mathrm{Be}$, practically no stratospheric ${ }^{7} \mathrm{Be}$ is contributed into the troposphere.

\subsection{Estimate of the Recycled ${ }^{10} \mathrm{Be}$ Component}

[17] The observation that the higher the amount of dust transported the higher the ${ }^{7} \mathrm{Be}$ concentration in the dust (section 3.1 above and Table 1) indicates that the dust scavenges efficiently "newly" produced ${ }^{7} \mathrm{Be}$. If the dust scavenges the long-lived ${ }^{10} \mathrm{Be}$ by a similar mechanism to ${ }^{7} \mathrm{Be}$ then the ${ }^{7} \mathrm{Be}$ in the traps provide an estimate for the recycled component of ${ }^{10} \mathrm{Be}$ in the dust settling in the Dead Sea drainage basin. The ${ }^{7} \mathrm{Be} /{ }^{10} \mathrm{Be}$ ratio however, may fluctuate during the dust transport due to Temporal fluctuations in the stratosphere-troposphere exchange (STE) rate [Heikkila et al., 2008] that may introduce variations in the ${ }^{7} \mathrm{Be} /{ }^{10} \mathrm{Be}$ ratio due to (a) the huge difference in the half lives of the two nuclides (factor of $\sim 10^{7}$ ) (b) the strong altitude dependence of the ${ }^{7} \mathrm{Be} /{ }^{10} \mathrm{Be}$ production ratio, and (c) the increase with altitude of the ${ }^{7} \mathrm{Be}$ atmospheric residence time. Apparently, the fluctuations in the ${ }^{7} \mathrm{Be} /{ }^{10} \mathrm{Be}$ ratio introduced by these three processes are small as suggested by: 1 . The good fit of a first order mass-balance model to the dust trap ${ }^{7} \mathrm{Be}$ inventories (Figure 3 ) implies that ${ }^{7} \mathrm{Be}$ fluctuations induced by short-term variations in STE were filtered out by the relatively long integration in the traps; 2 . During the long transport of dust from its origin in the Sahara the cosmogenic nuclides were most probably scavenged in different altitudes. Thus the altitude effect on the ${ }^{7} \mathrm{Be} /{ }^{10} \mathrm{Be}$ production ratio is minimized.

[18] Based on the ${ }^{7} \mathrm{Be}$ we estimate the flux of "newly" produced ${ }^{10} \mathrm{Be}$ (i.e., the total ${ }^{10} \mathrm{Be}$ flux minus the recycled component) into the Dead Sea drainage basin by the equation:

$$
\mathrm{F}_{10_{\mathrm{Be}}}=\left(\frac{\mathrm{P}_{10_{\mathrm{Be}}}}{\mathrm{P}_{7_{\mathrm{Be}}}}\right)_{\mathrm{mg}} \cdot \mathrm{F}_{7_{\mathrm{Be}}} \cdot \mathrm{e}^{\lambda_{7} \tau}
$$

Where $\mathrm{F}_{10_{\mathrm{Be}}}$ is the "newly" produced ${ }^{10} \mathrm{Be}$ flux; $\left(\frac{\mathrm{P}_{10_{\mathrm{Be}}}}{\mathrm{P}_{7 \mathrm{e}}}\right)_{\mathrm{mg}}$ is the mean global ${ }^{10} \mathrm{Be} /{ }^{7} \mathrm{Be}$ production ratio ( $\sim 0.5$ according to Masarik and Beer [1999]) which we use here due to the relatively small fluctuations in the ${ }^{10} \mathrm{Be} /{ }^{7} \mathrm{Be}$ ratio obtained when integrating over several months and long distances (see discussion in the paragraph above). It should be emphasized that the ${ }^{10} \mathrm{Be} /{ }^{7} \mathrm{Be}$ of 0.5 used in equation (4) is the global mean production ratio estimated by previous studies. We do not assume that this is the actual ratio in the dust. Substituting into equation (4) the ${ }^{7} \mathrm{Be}$ fluxes and residence times evaluated above, yield an estimate of the "newly" produced ${ }^{10} \mathrm{Be}$ fluxes for the Dead Sea region of $1200 \pm 360$ atoms $\mathrm{cm}^{-2} \mathrm{~d}^{-1}, 270 \pm 360$ atoms $\cdot \mathrm{cm}^{-2} \cdot \mathrm{d}^{-1}$ and $900 \pm 190$ atoms $\cdot \mathrm{cm}^{-2} \cdot \mathrm{d}^{-1}$ for summer-winter, fall and annual average, respectively. Our earlier study in the Dead Sea region estimated the annual ${ }^{10} \mathrm{Be}$ flux to be $4800 \pm$ 2400 atoms $\cdot \mathrm{cm}^{-2} \cdot \mathrm{d}^{-1}$ [Belmaker et al., 2008], much higher than the fluxes calculated above. While this discrepancy seems to suggest that Judean Desert dust contains a significant portion of recycled ${ }^{10} \mathrm{Be}$, it actually stems from the calculation procedure of our earlier study. The samples in the earlier study were collected at the beginning of winter, but the ${ }^{10} \mathrm{Be}$ flux calculation used the average annual dust flux of the Dead Sea region and not the winter dust flux [Belmaker et al., 2008]. Re-calculating the ${ }^{10} \mathrm{Be}$ flux in the Dead Sea region using the reported winter ${ }^{10} \mathrm{Be}$ concentration in dust $\left(1.6 \pm 0.8 \times 10^{8}\right.$ atoms.gr $^{-1}$ according to
Belmaker et al. [2008]) and the winter dust flux (1.8-6.8 $\times$

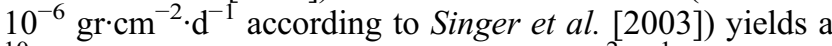
${ }^{10} \mathrm{Be}$ winter flux of $290-1100$ atoms $\cdot \mathrm{cm}^{-2} \cdot \mathrm{d}^{-1}$. This estimate is very similar to the winter flux of "newly" produced ${ }^{10} \mathrm{Be}$ as calculated from Equation 5, above $(1200 \pm$ 360 atoms $\cdot \mathrm{cm}^{-2} \cdot \mathrm{d}^{-1}$ ). The similarity between the flux of "newly" produced ${ }^{10} \mathrm{Be}$ as estimated here from the ${ }^{7} \mathrm{Be}$ data and the ${ }^{10} \mathrm{Be}$ flux estimated from direct ${ }^{10} \mathrm{Be}$ measurements (modified calculation of Belmaker et al. [2008]) indicates that the recycled ${ }^{10} \mathrm{Be}$ component in the Dead Sea region is potentially rather small. Since the ${ }^{10} \mathrm{Be}$ signal in the source region may build up for several years this result is surprising. Simultaneous ${ }^{10} \mathrm{Be}$ and ${ }^{7} \mathrm{Be}$ measurements on samples collected in the dust traps are needed to corroborate this conclusion.

\section{Summary and Conclusions}

[19] Atmospheric ${ }^{7}$ Be dry deposition was measured in the Judean Desert by the use of dust traps. These measurements provide one of the first estimates of the ${ }^{7} \mathrm{Be}$ flux in arid regions. The main results of the study are:

[20] 1. The summer-winter, fall and annual average dry deposition fluxes of ${ }^{7} \mathrm{Be}$ in the Judean desert are: $1.98 \pm$ $0.58 \times 10^{4}$ atoms $\cdot \mathrm{cm}^{-2} \cdot \mathrm{y}^{-1}, 5.3 \pm 0.72 \times 10^{4}$ atoms $\cdot \mathrm{cm}^{-2} \cdot \mathrm{y}^{-1}$ and $3.94 \pm 0.84 \times 10^{4}$ atoms $\cdot \mathrm{cm}^{-2} \cdot \mathrm{y}^{-1}$, respectively.

[21] 2. The mean atmospheric residence time of ${ }^{7} \mathrm{Be}$ in the Judean Desert is $220 \pm 45$ days.

[22] 3. The residence time of Judean Desert dust in the Dead Sea drainage basin is less than one year. This is a rather short residence time for desert areas, indicating that rare flood events in the drainage basin wash very efficiently into the deposition basin the airborne particles that were deposited during the dry season.

[23] $4 .{ }^{7} \mathrm{Be}$ inventories (atoms $\cdot \mathrm{cm}^{-2}$ ) in Judean Desert dust increase with time and do not reach steady state values within the time period between winter floods. If this scenario is true also for ${ }^{10} \mathrm{Be}$, than ${ }^{10} \mathrm{Be}$ in Lake Lisan sediments may be a proxy for paleo-flood frequencies.

[24] 5. Although contradictory to what we expected our results demonstrate that the recycled ${ }^{10} \mathrm{Be}$ component of Judean Desert dust is potentially small. Simultaneous ${ }^{10} \mathrm{Be}$ and ${ }^{7} \mathrm{Be}$ measurements on samples collected in the dust traps are needed to corroborate this conclusion.

[25] Acknowledgments. We wish to thank Marian Fujak for ${ }^{7} \mathrm{Be}$ analysis. This research was generously funded by a grant provided by the Israel Science Foundation (ISF).

[26] The Editor thanks James Kaste for his assistance in evaluating this paper.

\section{References}

Begin, Z. B., A. Ehrlich, and Y. Nathan (1974), Lake Lisan: The Pleistocene precursor of the Dead Sea, Bull. Geol. Surv. Isr., vol. 63, Geol. Surv. of Isr., Jerusalem.

Belmaker, R., B. Lazar, N. Tepelyakov, M. Stein, and J. Beer (2008), ${ }^{10} \mathrm{Be}$ in Lake Lisan sediments-A proxy for production or climate?, Earth Planet. Sci. Lett., 269, 448-457, doi:10.1016/j.epsl.2008.02.032.

Duenas, C., M. C. Fernandez, S. Canete, J. J. Perez-Barea, and M. Perez (2009), Effects of collector types in sampling of atmospheric depositiona fluxes, J. Environ. Radioact., 100, 198-202, doi:10.1016/j.jenvrad. 2008.11.014

Field, V. C., A. G. Schmidt, D. Koch, and C. Salyk (2006), Modeling production and climate-related impacts on ${ }^{10} \mathrm{Be}$ concentration in ice cores, J. Geophys. Res., 111, D15107, doi:10.1029/2005JD006410. 
Greenbaum, N., A. Ben-Zvi, I. Haviv, and Y. Enzel (2006), The hydrology and paleohydrology of the Dead Sea tributaries, in New Frontiers in Dead Sea Paleoenvironmental Research, edited by Y. Enzel, A. Agnon, and M. Stein, Geol. Soc. Am. Spec. Pap., 401, 63-93, doi:10.1130/ 2006.2401(05)

Haliva-Cohen, A. (2004), Mineralogy, petrology and isotopic composition of fine-grain detritial sediments of the Dead Sea group: Origin and Means of transportation, M.Sc. thesis, 86 pp., Heb. Univ. of Jerusalem, Jerusalem.

Heikkila, U., J. Beer, and V. Alfimov (2008), Beryllium-10 and beryllium-7 in precipitation in Dübendorf $(440 \mathrm{~m})$ and at Jungfraujoch $(3580 \mathrm{~m})$, Switzerland (1998-2005), J. Geophys. Res., 113, D11104, doi:10.1029/ 2007JD009160.

Heikkila, U., J. Beer, and J. Feichter (2009), Meridional transport and deposition of atmospheric ${ }^{10} \mathrm{Be}$, Atmos. Chem. Phys., 9(2), 515-527, doi:10.5194/acp-9-515-2009.

Hernandez, F., et al. (2008), Origin of observed high ${ }^{7}$ Be and mineral dust concentrations in ambient air on the Island of Tenerife, Atmos. Environ. 42, 4247-4256, doi:10.1016/j.atmosenv.2008.01.017.

Kaste, J. M., A. J. Elmore, K. R. Vest, and G. S. Okin (2011), Beryllium-7 in soils and vegetation along an arid precipitation gradient in Owens Valley, California, Geophys. Res. Lett., 38, L09401, doi:10.1029/ 2011 GL047242.

Katz, A., Y. Kolodny, and A. Nissenbaum (1977), The geochemical evolution of the Pleistocene Lake Lisan-Dead Sea system, Geochim. Cosmochim. Acta, 41(11), 1609-1626, doi:10.1016/0016-7037(77)90172-7.

Masarik, J., and J. Beer (1999), Simulation of particle fluxes and cosmogenic nuclide production in the Earth's atmosphere, J. Geophys. Res., 104(D10), 12,099-12,111, doi:10.1029/1998JD200091.

Neev, D., and K. O. Emery (1967), The Dead Sea, Depositional Processes and Environments of Evaporites, Bull. Geol. Surv. Isr., vol. 41, Geol. Surv. of Isr., Jerusalem.

Olsen, C. R., I. L. Larsen, P. D. Lowry, N. H. Cutshall, J. F. Todd, G. T. F. Wong, and W. H. Casey (1985), Atmospheric fluxes and marsh-soil inventories of ${ }^{7} \mathrm{Be}$ and ${ }^{210} \mathrm{~Pb}, J$. Geophys. Res., 90(D6), 10,487-10,495, doi:10.1029/JD090iD06p10487.

Othman, I., M. S. Al-Masri, and M. Hassan (1998), Fallout of ${ }^{7} \mathrm{Be}$ in Damascus City, J. Radioanal. Nucl. Chem., 238(1-2), 187-192, doi:10.1007/BF02385379.

Singer, A., E. Ganor, S. Dultz, and W. Fischer (2003), Dust deposition over the Dead Sea, J. Arid Environ., 53(1), 41-59, doi:10.1006/jare.2002.1023.

Stein, M. (2001), The sedimentary and geochemical record of NeogeneQuaternary water bodies in the Dead Sea basin-inferences for the regional paleoclimatic history, J. Paleolimnol., 26(3), 271-282, doi:10.1023/A:1017529228186.

Stein, M., et al. (1997), Strontium isotopic, chemical, and sedimentological evidence for the evolution of Lake Lisan and the Dead Sea, Geochim. Cosmochim. Acta, 61(18), 3975-3992, doi:10.1016/S0016-7037(97) 00191-9.

Todd, J., G. Wong, C. Olsen, and I. Larsen (1989), Atmospheric depositional characteristics of beryllium-7 and lead-210 along the southerneast Virginia coast, J. Geophys. Res., 94(D8), 11,106-11,116, doi:10.1029/ JD094iD08p11106.

Turekian, K. K., L. Benninger, and E. Dion (1983), ${ }^{7} \mathrm{Be}$ and ${ }^{210} \mathrm{~Pb}$ total deposition fluxes at New Haven, Connecticut and Bermuda, J. Geophys. Res., 88(C9), 5411-5415, doi:10.1029/JC088iC09p05411.

Yaalon, D. H., and E. Ganor (1975), Rates of aeolian dust accretion in the Mediterranean and desert fringe environment of Israel, in Quantitative Techniques for the Analysis of Sediments: An International Symposium; Proceedings of an International Symposium Held at the 9th International Sedimentological Congress in Nice, France, on 8 July 1975, edited by D. F. Merriam, pp. 169-173, Pergamon, Oxford, U. K.

J. Beer, EAWAG, Postfach-611, CH-8600 Duebendorf, Switzerland. R. Belmaker, B. Lazar, and M. Stein, Institute of Earth Sciences, Hebrew University of Jerusalem, Givat-Ram Campus, Jerusalem 91904, Israel. (reuven.belmaker@mail.huji.ac.il) 